\title{
A FULLY INTEGRATED BROADBAND AMPLIFIER WITH 161\% 3-dB BANDWIDTH
}

\author{
WEN-CHIEH WU \\ Graduate Institute of Electrical Engineering, National Taiwan University \\ Room 418, Graduate Institute of Electrical Engineering, National Taiwan University, Roosevelt Rd., \\ Sec. 4, No.1, 106, Taipei, Taiwan, R.O.C. \\ E-mail: wcw@epicenter.ee.ntu.edu.tw \\ HUEI WANG \\ Graduate Institute of Communication Engineering, National Taiwan University \\ Room 317, Graduate Institute of Communication Engineering, National Taiwan University, \\ Roosevelt Rd., Sec. 4, No. 1, 106, Taipei, Taiwan, R.O.C. \\ E-mail: hueiwang@ew.ee.ntu.edu.tw \\ HAO-HSIUNG LIN \\ Graduate Institute of Electrical Engineering, National Taiwan University \\ Room 419, Graduate Institute of Electrical Engineering, National Taiwan University, Roosevelt Rd., \\ Sec. 4, No.1, 106, Taipei, Taiwan, R.O.C. \\ E-mail: hhlin@epicenter.ee.ntu.edu.tw
}

\begin{abstract}
A broadband, low voltage supply, fully integrated monolithic amplifier using GaAs high electron mobility transistor was described. At $2 \mathrm{~V}$ power supply, it has $14.5 \pm 0.4 \mathrm{~dB}$ of gain from 1 through $6 \mathrm{GHz}$. The 3-dB bandwidth is from $800 \mathrm{MHz}$ to $7.4 \mathrm{GHz}$. The bandwidth is $161 \%$. More than $15 \mathrm{~dB}$ gain is attainable if the supply voltage is increased to $3 \mathrm{~V}$.
\end{abstract}

\section{Introduction}

Broadband amplifiers using GaAs covering several octaves have been reported by a number of researchers in the literature [1-5]. Most of them professed from dc to tens of $\mathrm{GHz}$ using distributed circuit topology [1-2]. For distributed amplifiers, circuit construction is complicated, power consumption is high, and the die area is large, which will increase the cost of production. Resistive feedback topology is suitable for multi-stage amplifiers [3-4]. For this single-stage broadband amplifier, it is difficult to have a source resistor that is large enough to broadening the bandwidth of the amplifier and small enough to get a small voltage difference between gate and source of the HEMT device. Thus, lossy matched amplifier is a better way to solve this problem [5]. The lossy matched amplifier is attractive for its simplicity, compact size and low cost. At this time and the near future, different communication equipment use different frequencies ranging from $900 \mathrm{MHz}$ to 5.7 GHz. A broadband amplifier which provides very smooth gain from $900 \mathrm{MHz}$ to $6 \mathrm{GHz}$ working under single battery power supply voltage with simple circuit construction on small chip area will be a practical and useful circuit for multi-band portable wireless system.

\section{Circuit Design}

The amplifier is designed for $50 \Omega$ systems. Fig. 1 shows a schematic circuit diagram of the amplifier. The dotted line shows the chip boundary. The $0.2 \mu \mathrm{m}$ GaAs PHEMT process is provided by Philips in France. In order to provide enough gain at higher frequency, a $6 \times 50 \mu \mathrm{m}$ transistor was chosen. This transistor provides $\mathrm{G}_{\max }=17 \mathrm{~dB}$ at $7.4 \mathrm{GHz}$. Lossy matched method is used to design this broadband amplifier in stead of feedback design. As shown in Fig. 1, while parallel connecting lossy matched resistor $R_{1}$ at input port of the transistor, $S_{11}$ was effectively pulled into Smith chart center. A quite good input impedance matching will be obtained at bandwidth from 1 to $6 \mathrm{GHz}$ after connecting an inductor $\mathrm{L}_{i}$ at input port. At output port, series inductance $\mathrm{L}_{\mathrm{o}}$ is the only matching element. Drain port 
voltage source comes through shunt-connected RF choke inductor $L_{d}=9.9 \mathrm{nH}$. Because the lowest frequency of this circuit is $900 \mathrm{MHz}$, inductor $\mathrm{L}_{\mathrm{d}}$ value can not be lowered any more. Simulated results show that $9.9 \mathrm{nH}$ inductor will resonate at frequencies higher than $5.6 \mathrm{GHz}$ and the inductor changes to be capacitive. To avoid the resonance, $\mathrm{L}_{d}$ is divided into three $3.3 \mathrm{nH}$ inductors and series connected, since the resonant frequency of $3.3 \mathrm{nH}$ inductor is $14 \mathrm{GHz}$, which is high enough for the operating frequency of this amplifier. In the bias network, $C_{g}$ and $C_{d}$ are used for $R F$ bypass capacitors. Resistor $R_{g}$ is used to enforce the isolation between RF and DC power supply. Series connected capacitors $C_{i}$ and $C_{o}$ were used for circuit matching as well as dc block. Large $C_{i}$ value and small $\mathrm{C}_{\mathrm{o}}$ value are aimed to have a more smooth gain on the broadband range. Fig. 2 shows a photograph of the amplifier with chip size of $1.5 \times 1 \mathrm{~mm}^{2}$.

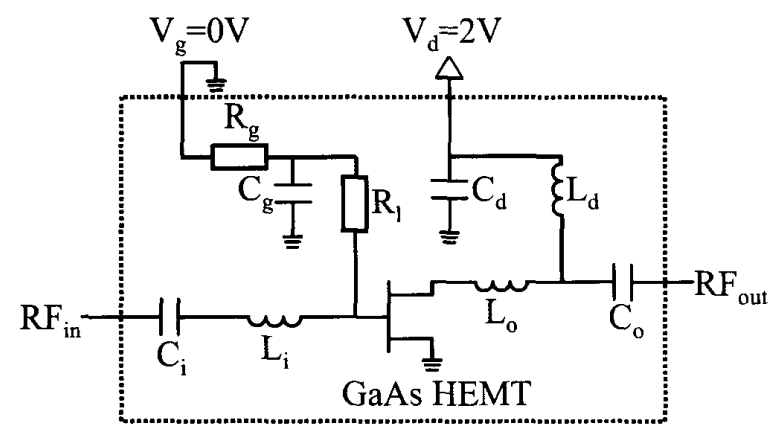

Fully Integrated Circuit Boundary

Figure 1. Schematic of the broadband amplifier.

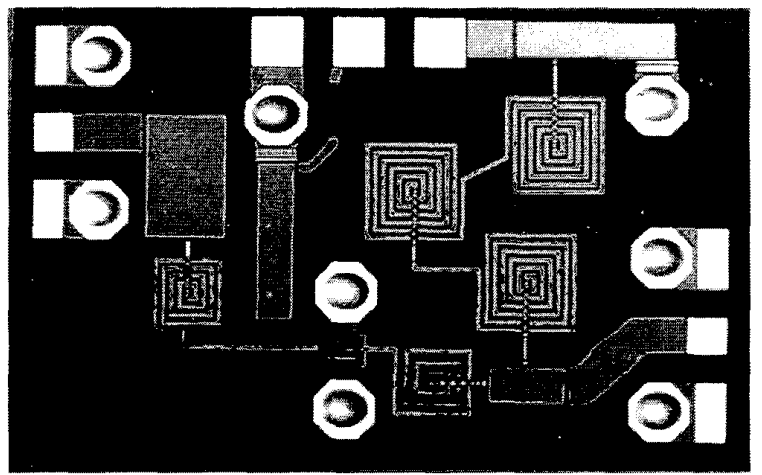

Figure 2. Photograph of the broadband amplifier.

\section{Simulation Results and Measurement}

Fig. 3 shows simulated and measured results for small signal gain and return losses of the amplifier. When power supply voltage is $2 \mathrm{~V}$, simulated amplifier gain $S_{21}$ is between $14 \pm 0.5 \mathrm{~dB}$ at frequency ranging from $1 \mathrm{GHz}$ to $6 \mathrm{GHz}$ as dashed line in Fig. 3. Both input and output return losses are better than $10 \mathrm{~dB}$.

The chip was measured on wafer using $50 \Omega$ coplanar ground-signal-ground (GSG) probes. Under $2 \mathrm{~V}$ power supply, measured small signal gain is between $14.5 \pm 0.4 \mathrm{~dB}$ while frequency ranging from 1 to $6 \mathrm{GHz}$ as solid line shown in Fig. 3. The 3-dB bandwidth is from $800 \mathrm{MHz}$ to $7.4 \mathrm{GHz}$. The bandwidth is $161 \%$. The return losses of input and output are almost higher than $10 \mathrm{~dB}$. Measured results agree well with simulated ones as shown in Fig. 3. If the power supply is increased to $3 \mathrm{~V}$, amplifier gain can reach up to $15.2 \mathrm{~dB}$.

Fig. 4 shows the gain and output power vs. input power. When the power supply is $2 \mathrm{~V}$ and operation 
frequency is $3.5 \mathrm{GHz}$, output $1-\mathrm{dB}$ compression point is $\mathrm{P}_{1 \mathrm{~dB}}=18.1 \mathrm{dBm}$, and the third order intercepted point IP3 is $25.8 \mathrm{dBm}$. Measured noise figure is shown in Fig. 5, which is $4.7 \mathrm{~dB}$ at 1 $\mathrm{GHz}$ and increase to $5.5 \mathrm{~dB}$ at $6 \mathrm{GHz}$. In general, the noise figure of a lossy matched amplifier is worse than that of other approaches because of the resistor $R_{i}$. There is a tradeoff between gain bandwidth and noise figure. The circuit is stable under all bias conditions.

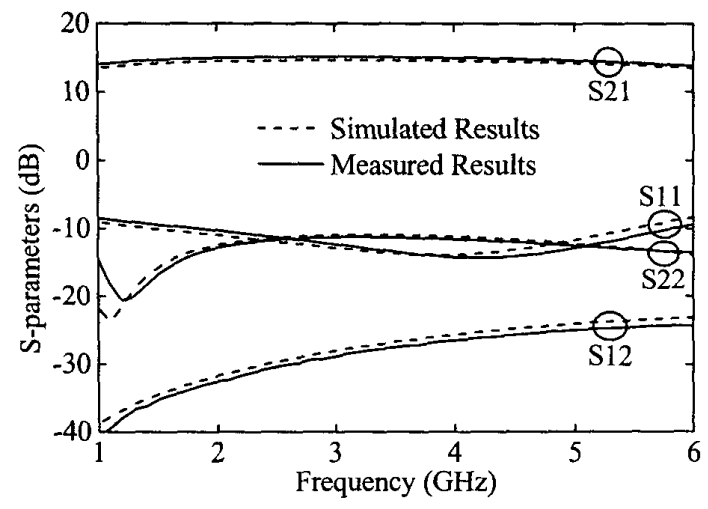

Figure 3. Simulated and measured results of S-parameters under 2V-power supply.

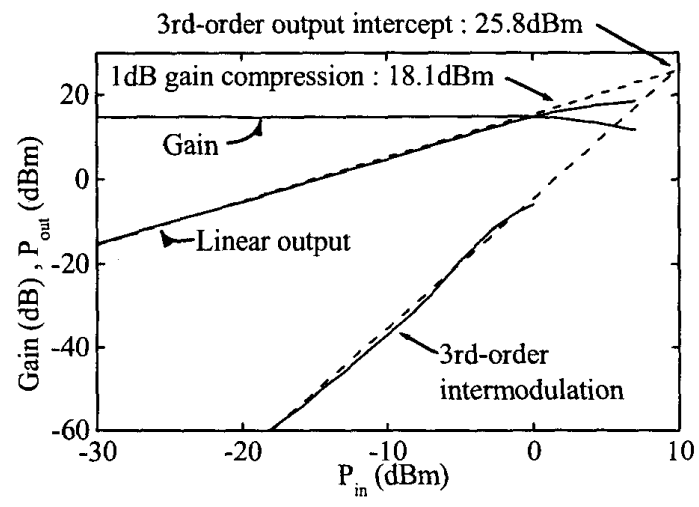

Figure 4. Intermodulation characteristics of the broadband amplifier for a two-tone signal at $3.5 \mathrm{GHz}(\Delta \mathrm{f}=100 \mathrm{MHz}$ )

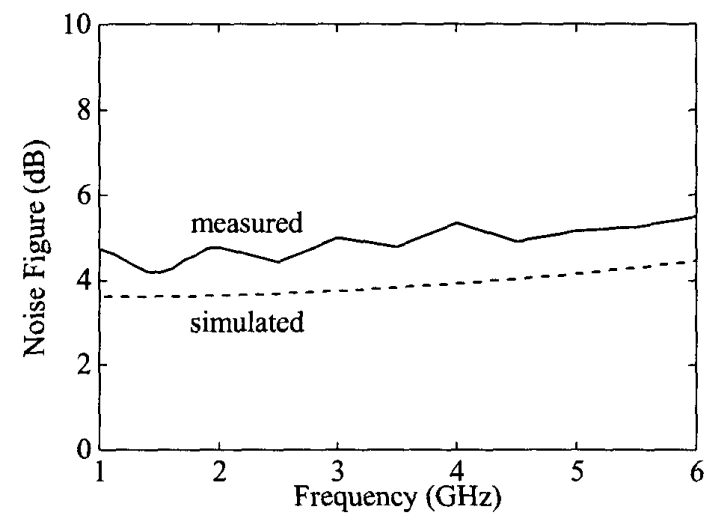

Figure 5. Simulated and measured noise figure of the amplifier. 


\section{Summary}

A fully integrated lossy matched broadband amplifier with $0.2 \mu \mathrm{m}$ gate length GaAs HEMT has been designed, fabricated and tested. Under 2V-power supply, small signal gain $S_{21}$ is between $14.5 \pm 0.4$ $\mathrm{dB}$ and 3-dB bandwidth is from $800 \mathrm{MHz}$ to $7.4 \mathrm{GHz}$. The bandwidth is $161 \%$. Increase the power supply to $3 \mathrm{~V}$, amplifier gain can reach up to $15.2 \mathrm{~dB}$. Noise figure is better than $5.5 \mathrm{~dB}$ at $6 \mathrm{GHz}$. The output $1-\mathrm{dB}$ compression point $\mathrm{P}_{1 \mathrm{~dB}}$ is $18.1 \mathrm{dBm}$ and the third order intercepted point IP3 is 25.8 $\mathrm{dBm}$. Comparing the simulated and measured results, good agreement is observed.

\section{Acknowledgements}

The authors would like to acknowledge Dr. H. K. Chiou of Chung-Shan Science and Technology Institute for his valuable suggestions and help in the testing, Dr. K. W. Huang of Nano Device Laboratory for their help on measuring. Thanks also go to Chip Implementation Center of Taiwan for their foundry service coordination effort.

\section{References}

[1] B. Agarwal, "80 GHz Distributed Amplifiers with Transferred-Substrate Heterojunction Bipolar Transistors", IEEE MTT-S Digest, Vol. 2, pp 529-532, 1998.

[2] Y. Baeyens, "A 74-GHz Bandwidth InAlAs/InGaAs-InP HBT Distributed Amplifier with 13-dB Gain", IEEE Microwave and Guided Wave Letters, Vol. 9, pp 461-463, November 1999.

[3] B. Agarwal, "Broadband Feedback Amplifiers with AlInAs/GalnAs Transferred-Substrate HBT", Electronics Letters, Vol 34, No. 13, pp 1357-1358, June 1998.

[4] K. W. Kobayashi, "GaAs Heterojunction Bipolar Transistor MMIC DC to $10 \mathrm{GHz}$ Direct-Coupled Feedback Amplifier", IEEE GaAs IC Symposium, pp 87-90, 1989.

[5] Yasushi Ito, "GaAs HEMT Lossy Match Amplifiers", IEEE MTT-S Digest, pp347-350, 1988. 